\title{
Towards a New Mobile Educational Model
}

\author{
Adaptation of the Method for Engineering Learning Systems MISA
}

\author{
Ouiame Filali Marzouki, Mohammed Khalidi Idrissi, Samir Bennani \\ Computer Science Department, LRIE Laboratory, RIME Team Mohammadia School Engineers (EMI), Rabat, Morocco \\ Mohammed V ${ }^{\text {th }}$ University Agdal, AV. Ibn Sina Agdal Rabat BP. 765, Morocco \\ ouiamefilali@gmail.com; khalidi@emi.ac.ma; sbennani@emi.ac.ma
}

\begin{abstract}
-the development of mobile technologies and wireless networks encourages more research on Mobile Learning. Reviewing irregular verbs on a bus or organizing a training schedule on a Smartphone is becoming more common today. Mobile learning complements and enhances existing learning systems. Its development has been slowed in the early 2000 s by both technical limitations and lack of dedicated teaching models. This article focuses on educational issues and proposes a solution by adopting the Method for Engineering Learning Systems MISA. Our work aims to identify basic elements, key characteristics and dimensions for developing the appropriate content for mobility. These elements are the basis for customization of the MISA method. Indeed, the different steps of MISA are governed by operating principles which ensure greater consistency and flexibility. Taking into account the specifications of Mobile learning in the development of these principles, we can adapt MISA to design a mobile learning system.
\end{abstract}

Keywords- mobile learning, e-learning, MISA, pedagogical scenario, learning activities, connectivism.

\section{INTRODUCTION}

The Internet today is a window into its users' perceptions, their ideas and their way of life [1]. This is enhanced by the development of wireless networks and mobile devices. These technologies are influencing our social habits. Learning systems can only follow these changes to better support learners, their needs and their preferences. This is possible today with mobile learning or learning through mobile devices. Mobile Learning is a new paradigm that has been the subject of countless research projects during the past decade. The first work performed was completely techno centered. It focused on the use of new mobile technologies and the users' attitudes towards these technologies, where after it focused on the application of existing learning theories (e.g. theory of activity). Currently, we are more interested in teaching and learning problems of mobile learning in order to formalize this paradigm by new models and methods.

For this purpose, we have chosen to apply the Method for Engineering Learning Systems (MISA) to a mobile learning context. The choice of this method is due to its flexibility and its ability to design different learning systems through its various principles. MISA defines multiple operating principles governing the management of instructional design process, namely progression principles, customization principles, general orientation principles and axes coordination principles. Each principle specifies different groups of subjects dealing with pedagogical approaches, scenarios and learning activities, modes and media delivery, etc. Adapting MISA to the design of a mobile learning system returns to customizing these principles by adding topics dedicated to mobility.

This work aims to analyze the mobile learning to highlight the main features and key characteristics of a suitable content for mobile terminals. Furthermore, it explores opportunities offered by this new concept and dimensions to consider when developing a mobile learning system. This done, we will present our vision of adapting the MISA method by exploiting the elements already defined. These specifications will be integrated through the operating principles of the MISA method to adapt it to our mobile environment.

\section{MOBILE LEARNING}

Mobile learning is defined as "the use of mobile devices that can connect to the Internet for educational contexts" [5]. Despite its clarity, this definition raises many questions as we seek to identify the main characteristics of mobile learning. Indeed, this paradigm is not only based on the use of new technologies, but also reveals new features and dimensions for consideration. Wang, Wiesemes and Gibbons associate three qualifications with this definition to delimit the mobile learning concept: mobility, the use of mobile devices, and communication exchange among participating communities [5].

Highlighting these qualifications presents mobile learning as a way of learning imposed by and for the satisfaction of the learners' increased need for mobility in the $21^{\text {st }}$ century. This covers their continuous movement between different environments and across multiple subjects and disciplinary contexts. Mobile learning provides specific educational content via mobile devices. These devices extend learning beyond formal educational settings, through personal experiences at the workplace, while traveling, or in the waiting room of a doctor to take just a few examples. They allow more interaction and promote learners' communicative nature. They also meet their need for exchange and collaboration thus building understanding among participating communities.

\section{A. Rationale for mobile learning}

The mobile phone has become the first media in the world with 4 billion subscriptions (Ahonen, 2010) [21]. A report by Wireless Intelligence in 2010 accounted for 547.5 million subscribers in Africa [6]. The use of mobile devices in principle varies between emails consultation, social networks 
and web research. Predictions state that by 2020 the majority of Internet users will connect via mobile technology [21]. Added to this the growing need for lifelong learning and knowledge acquisition at the appropriate times; mobile technologies prove to be an effective solution to our knowledge society. Predictions have also been made regarding Long Term Evolution (LTE) 4G-engaged devices sales, to rise by $202.5 \%$ to 275 million units in 2013 compared to 2012 [2].

The rationale for mobile learning, according to Tapscot, is that $21^{\text {st }}$ century learners have "grown up digital" and that they "expect it." [5]. Today's young people adopt mobile technologies for different tasks in their daily lives. Mobile devices allow them among other to share ideas on micro blogs, seek instant information on forums, take notes and configure notifications for important appointments.

On its part, the evolution of automatic summarization tools can facilitate the content delivery throw mobile devices. [4] highlights the role of these tools for managing the vast available online literature. The process of summarization reduces the complexity and length of the original documents, providing the visibility of the subject matter and key ideas of the work. Some tools quality is comparable to that of the human extracts [4].

Indeed, with the advent of Web 2.0 and the move towards Web 3.0, education must follow these technological advances and evolve in parallel. This becomes possible with mobile learning that promotes the movement towards connectivist approaches where educators, learners, networks, connections, media, resources and tools no longer constitute a single entity. This new emerging entity has the potential to meet the needs of individual learners, teachers and even society [1].

Studies on the perception of students and educators and their readiness to use mobile learning have been conducted [7] [22]. Contrary to what one might expect, the results show that these two main actors of the learning process are not conservative toward mobile leaning. Rather, they are willing to explore and try new technologies.

Mobile technologies allow today's youth to determine what they want to learn and develop their own learning objectives using their own devices. They give them the opportunity to train their learning communities and use the methods and means that suit them best. The current changes are such that learners are no more than consumers of knowledge. Teachers in turn, must increasingly focus on contextual knowledge, problem solving skills and creative processes [19]. In this context, the mobile learning introduces new learning situations that promote these competencies.

Mobile learning encourages the introduction of connectivist approach. Indeed, for the inventors of this approach, George Siemens and Stephen Downes, "The existing learning models no longer reflect the reality that we live in our digital society. We are developing new knowledge constantly while exchanging, sharing and critiquing through social networks and blogs. This state of generalized connection is a learning process in itself, which is difficult to satisfy by linear pathways and unilateral transfer of knowledge and memorization from a set of limited and predetermined corpus of data" [16].

Connectivist approach is based on five components: communication, collaboration, motivation, creativity and integration. The principles of mobile learning and its specificities match largely the components of this approach through the features offered by mobile technologies insofar as they allow instant communication between different information resources. This ensures a greater exchange of ideas and resources through community, creativity in new learning activities introduced such as mobile tagging, geolocation, multimedia, etc.

New technologies often sold as "revolutionary" are used to do the same old activities. [5]. A review of the use of mobile devices in the majority of mobile learning projects confirms this statement. Therefore we do not really enjoy the potential of mobility. The latter provides continuity in the learning experience through different contexts and allows the design of new learning situations adapted to learners' daily life. It is necessary then to determine the main characteristics of mobile learning that distinguish it from other learning formats in order to realize its potential.

\section{B. Mobile learning key characteristics}

Based on a literature review of the work dealing with mobile learning and findings concerning the results obtained, we have identified a set of specifications for a mobile learning system. It is a learning style that provides content suitable for limited features of mobile devices, for the mobile context of learners and their need for speed and relevance in obtaining information.

The mobile learning system is:

- Informal, contextual, situated and authentic; since mobile technologies extend learning in more stimulating environments than classrooms and allow learners to investigate real problems in which they are involved. They also facilitate obtaining relevant information in context to make connections between formal knowledge and personal experience. Experience shows that young people learn more effectively in such conditions [14].

- Immediate, appropriate, just in time, everywhere and anytime: the learner can view a simulation of the photoelectric effect in a physics course or do an online search of a painting during a visit to a museum. The data are obtained when and where necessary as required by the learner.

- Personalized: Mobile learning promotes effective learning. And it lies to its ability to recognize diversity, difference and individuality in the way it is developed, provided and supported. It takes into account the context and history of each learner [12].

- Personal, individualistic, and learner centered: young people have special relationships with their mobile devices creating an environment that reflects the identity of the owner, his lifestyle and his interests. The 
extension of these technologies for learning context develops this environment even more and makes it more personal and complete. "It's not what you know, it's the device you know" says Nicola Louise who argues that learners have more confidence in using their own technology which has great impact on the learning process [9].

- Complementary: Mobile tools are considered an extension to other learning tools [17]. Furthermore, only certain types of content and activities are appropriate for these devices. A series of studies of mobile learning indicate that these tools are used effectively to stimulate interest in the first delivery of content to increase motivation and monitor learning. [17].

The technical limitations of mobile devices make the educational content:

- Short, simple and interactive: learners should be able to benefit from their small fragments of time for learning. Viewing conference videos, making a quiz or posting a question in a forum during a trip by train are examples of possible activities with mobile devices. We can notice that the mobile learning projects using SMS and Podcasts have been the most successful.

- Targeted and specific: mobility must guide and support students and teachers in new learning situations where and when this is necessary. The content must be adapted to the context, providing information on the location and locus of interest according to the learners' preferences [17].

Finally the application or service developed for mobile learning should be:

- Attractive and easy to use: It should possess a pleasing visual design, a suitable interaction style and a certain agreeableness to give pleasure to interact [13]. It must have something 'sticky' to encourage students to return. [10].

\section{ADAPTING MISA METHOD FOR A MOBILE ENVIRONMENT}

The main limitation of mobile learning is the lack of teaching strategies and methods by which it can be integrated into the formal learning process. A UNESCO report notes that this paradigm has been long considered an extension of elearning which has diverted researchers to create a new pedagogy for mobile learning. [10]. In addition, the majority of researches are based on student feedback about the use of mobile technologies and their interaction and attitude towards the Mobile Learning approach [11]. We must now abandon the reuse of existing theories and the focus on the use of new technologies. It is necessary to develop design methods for the learning process to fit the use of mobile learning and promote learners' mentoring. Rather, we must consider the methodological and didactic issues to develop appropriate pedagogical models.

From the following, we will detail our vision for the formalization of mobile learning. We will present both the requirements to be met in order to obtain an effective conceptual model of mobile learning and mobile tools associated with each of them. This will determine the maturity of mobile learning through its ability to meet these requirements.

\section{A. Considerations in designing a mobile learning system}

To design mobile learning situations, we must ask what teaching strategies work best for which technological tools. We should also highlight what distinguishes mobile learning as the fact that it is based on the mobility of learners across time, space and content and that is centered on the context. [15].

Mobile learning is learning which must adopt a specific pedagogical approach taking into account the components of the learning process (Table 1).

It should promote the potential of Web 2.0 in terms of exchange and collaboration (Table 2).

The mobile learning system allows introducing the connectivist approach to education systems and promoting existing approaches across multiple teaching activities enabled by mobile technologies (table 3 ).

Mobile learning must be designed as an extension to other learning formats. The main activity being done in-class or online, mobile devices can be used to enliven, enrich and add variety to traditional courses. Several mobile features help meet this characteristic. It cites podcasts, Reminders, Mobile blogging, etc.

Mobile learning should be designed to promote learners' skills in terms of communication and collaboration.

Mobile learning must take into account the criteria for effective learning:

- Learner-centered: Built on the skills and knowledge of learners, allowing them to reason from their own experience.

- Knowledge centered: The program is built on a solid foundation of knowledge validated, taught effectively and with an inventive use of concepts and methods.

- Evaluation centered: The evaluation should be adapted to the ability of learners, offering diagnostic and formative guidance built on success.

- Community centered: Successful learners form a supportive community, sharing knowledge and help less gifted students.

TABLE I. ASSOCIATED MOBILE TOOLS TO A LEARNING PROCESS COMPONENTS

\begin{tabular}{|l|c|}
\hline \multicolumn{1}{|c|}{ Components } & Mobile Tools \\
\hline $\begin{array}{l}\text { To inform/ to find out: } \\
\text { resources to consult }\end{array}$ & $\begin{array}{l}\text { Multimedia (Podcasting, Photos), Mobile } \\
\text { RSS, Mobile social networks, SMS, etc. }\end{array}$ \\
\hline $\begin{array}{l}\text { To interact: Communication } \\
\text { and collaboration tools }\end{array}$ & $\begin{array}{c}\text { Mobile photo/ video/ Voice, Blogging, } \\
\text { SMS, Flux RSS, Social Networks, } \\
\text { Forums, etc. }\end{array}$ \\
\hline $\begin{array}{l}\text { To motivate and activate: } \\
\text { Organization tools }\end{array}$ & $\begin{array}{c}\text { To do lists, Notes, Calendars, Reminders, } \\
\text { SMS, etc. }\end{array}$ \\
\hline
\end{tabular}




\begin{tabular}{|c|c|}
\hline Components & Mobile Tools \\
\hline To produce: evaluation & $\begin{array}{l}\text { Mobile assessment quizzes, Mobile } \\
\text { recording tools, Mobile wikis, etc. }\end{array}$ \\
\hline
\end{tabular}

TABLE II. ASSOCIATED MOBILE TOOLS TO WEB 2.0 EXCHANGE TYPES

\begin{tabular}{|c|c|}
\hline Exchange types & Mobile tools \\
\hline One to one & $\begin{array}{l}\text { SMS/MMS, E-mails, Mobile blogging, } \\
\text { etc. }\end{array}$ \\
\hline $\begin{array}{l}\text { One to Many and Many to } \\
\text { One }\end{array}$ & \multirow{2}{*}{$\begin{array}{l}\text { Mobiles Forums, Mobile Community } \\
\text { Networks, Podcasting, Mobile Micro } \\
\text { blogging }\end{array}$} \\
\hline Many to Many & \\
\hline
\end{tabular}

During the implementation of a mobile learning system, the learning experience should be divided into a sequence of activities and for each activity specify the following. [14]:

- The location of the activity: classroom, lab, internal or external.

- Adaptive technology and available technology.

- The content: text, diagrams, videos, etc.

- The amount of data to be manipulated.

- The necessary timing schedule of the activity.

- The technical requirements of the activity.

We have designed a scheme (Fig. 1) to describe the process of a standard learning activity with the use of mobile technologies. We have detailed the different steps in order to identify those that can be implemented on mobile devices. The main activity being done in-class or online, we have associated a set of appropriate mobile tools to other activities.

\section{B. Adapting the method for Engineering learning systems MISA}

Mobile technologies influence the teaching and learning process. Educational systems must follow these changes and develop design methods and modeling taking into account mobility. For this we chose the method for engineering learning systems MISA.

MISA is a generic method of instructional design. It facilitates the construction of varied scale learning systems, from a single learning unit to several courses including a variety of modules and learning activities. MISA offers

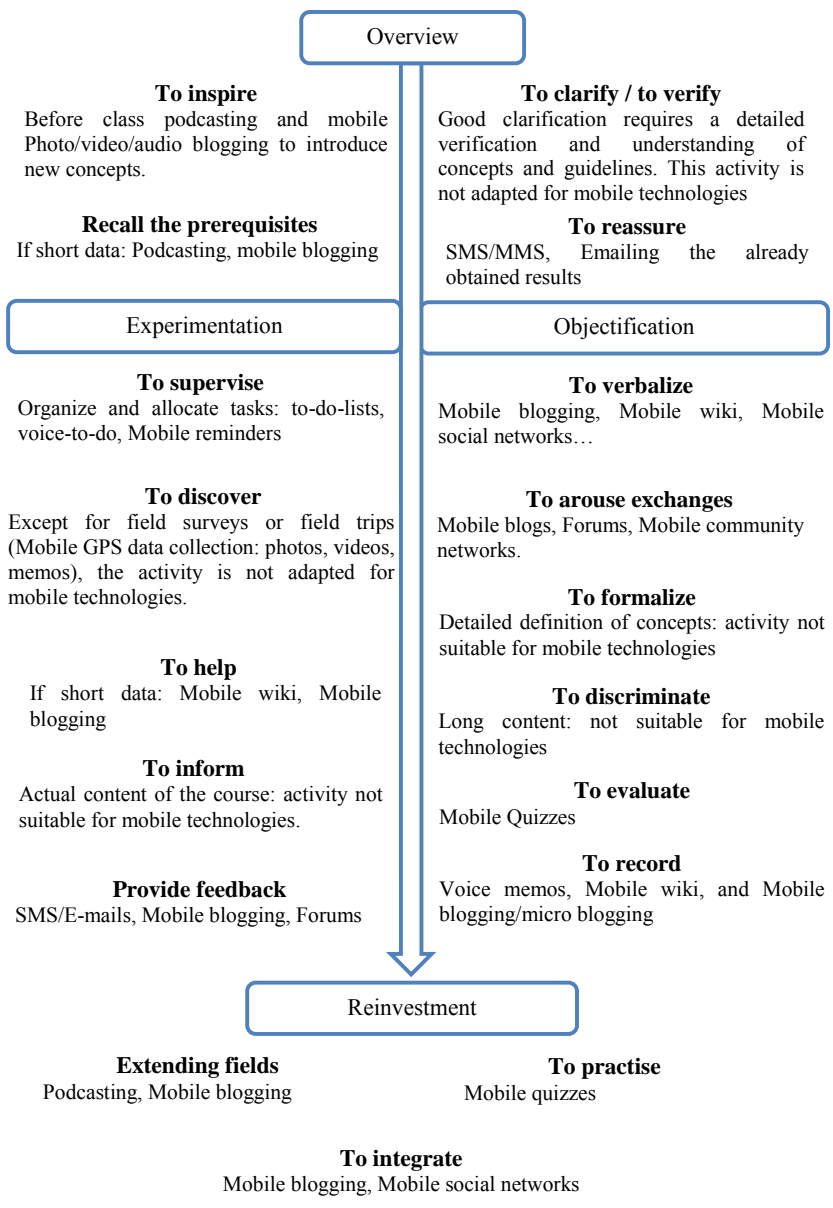

Fig. 1. Detailed process of a mobile learning activity

guarantees of consistency and makes visible the various processes. It provides templates that focus efforts and minimize design time [18].

The method is based on a philosophy consisting of the decomposition of the learning system in four areas, namely the field of knowledge, the instructional field, the learning materials field, and the delivery field. It describes six phases and four axes. The phases are:

- Defining problem and customizing MISA

- Defining preliminary solution

- Building learning system architecture

TABLE III. ASSOCIATED MOBILE TOOLS TO DIFFERENT PEDAGOGICAL APPROACH

\begin{tabular}{|l|c|c|}
\hline \multicolumn{1}{|c|}{ Pedagogical approach } & Principals methods & Mobile tools \\
\hline Behaviorist & Rapid feedback and monitoring & Mobile quizzes, Mobile reminders, etc. \\
\hline Constructivist & $\begin{array}{c}\text { Collaborative learning } \\
\text { Experiential learning } \\
\text { Problem-based learning } \\
\text { Project-based learning }\end{array}$ & $\begin{array}{c}\text { Mobile micro-blogging, Mobile } \\
\text { collaboration, Mobile Maps } \\
\text { application, Mobile social networks }\end{array}$ \\
\hline Individualistic & $\begin{array}{c}\text { Personalized programs } \\
\text { Modular education } \\
\text { Learner self-management }\end{array}$ & $\begin{array}{c}\text { Mobile check-lists, Rubrics, Quizzes, } \\
\text { Mobile wikis, Podcasting, etc. }\end{array}$ \\
\hline Connectivist & $\begin{array}{c}\text { Interaction network } \\
\text { Online community } \\
\text { Social learning }\end{array}$ & $\begin{array}{c}\text { Mobile bookmarking, Mobile social } \\
\text { tagging, Podcasting, Mobile blogging, } \\
\text { Mobile forums, etc. }\end{array}$ \\
\hline
\end{tabular}




\begin{tabular}{|c|c|c|}
\hline Pedagogical approach & Principals methods & Mobile tools \\
\hline & Informal learning & \\
\hline
\end{tabular}

- Designing instructional materials

- Producing and validating materials

- Preparing delivery of the learning system

The four axes are:

- Knowledge and competency axis

- Instructional axis

- Media axis

- Delivery axis

Phases and axes of the method are regulated by operating principles governing the different steps of the method.

These principles are of four types namely the general orientation principles, axes coordination principles, customization principles and phase progression principles. MISA uses the thirty five documentation elements (ED) concept, which is the methodological product of the different steps. Depending on the complexity of the learning system, the instructional designer can retain only seven documentation elements.

The choice of the MISA method as a method of designing a mobile learning system returns to its flexibility and consistency. MISA can be customized to suit the instructional designers' needs regardless of the size of the organization, the type and scope of the designed learning system or the available human, material, and financial resources. Designers do not have to produce all documentation elements or go through all the steps of the method. This flexibility and consistency is largely based on the four groups of operating principles previously mentioned. The diagram (Fig. 2) below shows the MISA method and its operating principles [20].

MISA provide four types of models: the knowledge and competency model, instructional model, learning material model, and the delivery model. The knowledge model defines and structures the knowledge as well as skills to be acquired by learners. Such a model promotes learner-centered and knowledge-centered approaches which are more suitable for mobile contexts and for effective learning systems.

Adapting MISA to a mobile context modifies its operating principles. At the general orientation principles and customization principles in particular we should note the recommendations and specifications appropriate for a Mobile Learning system. We must consider different teaching approaches introduced by the mobile learning, including connectivism and the types of activities that it generates. One must also consider the constraints presented on delivered content, the tools used, interactivity and sharing between users. We should respect dimensions as detailed previously as the complementary, informal and contextual characters of mobile learning.
Indeed, every principle of MISA method treats a group of subjects as shown in the Following.

The general orientation principles specify the theoretical approaches behind MISA. They offer varied pedagogical approaches in the construction of the learning system, and its delivery mode and support media. These principles are set at the beginning of each axis of the method. This group of principles contains four sub principles; instructional model orientation principles, material development orientation principles and delivery orientation principles.

- Instructional model orientation principles cover seven different topics: the type of learning event Network, types of learning scenarios, collaboration principles, instruments and resources, evaluation of learning, scenarios adaptability, and integrative concept.

- Material development orientation principles guide the media materials to ensure consistency while designing the learning system. They focus on four topics: the types of materials, their support, their interaction and their forms.

- Delivery orientation principles concern especially human resources needed to use the learning system, tools and means of communication, services and operating environments. They concern eleven groups of subjects: mode delivery types, means of communication, tools, delivery periods, delivery time, delivery locations, composition and groups' management, evaluation objectives, assessment actors, trainers and facilitators, and learning system evaluation.

The principles outlined above were summarized and modeled by GMOT knowledge and competencies modeling tool for better visibility. The figure (Fig. 3) shows the different operating principles of the MISA method [19].

Our approach aims to apply the features and specifications of mobile learning already mentioned to these different principles of MISA.

Indeed, in a mobile context the general orientation principles take into account pedagogical approaches introduced by mobile learning, including connectivism. This approach generates new forms of activities, collaboration and evaluation. In addition, the content delivered via mobile devices should be brief, concise and interactive which will increase the granularity of learning units. These constraints will influence learning event network types, learning scenarios types, collaboration principles and learning evaluation.

Also, these constraints will introduce new types of resources privileged by mobile devices such as simulations, synthetic schemes, guided tours, etc. 


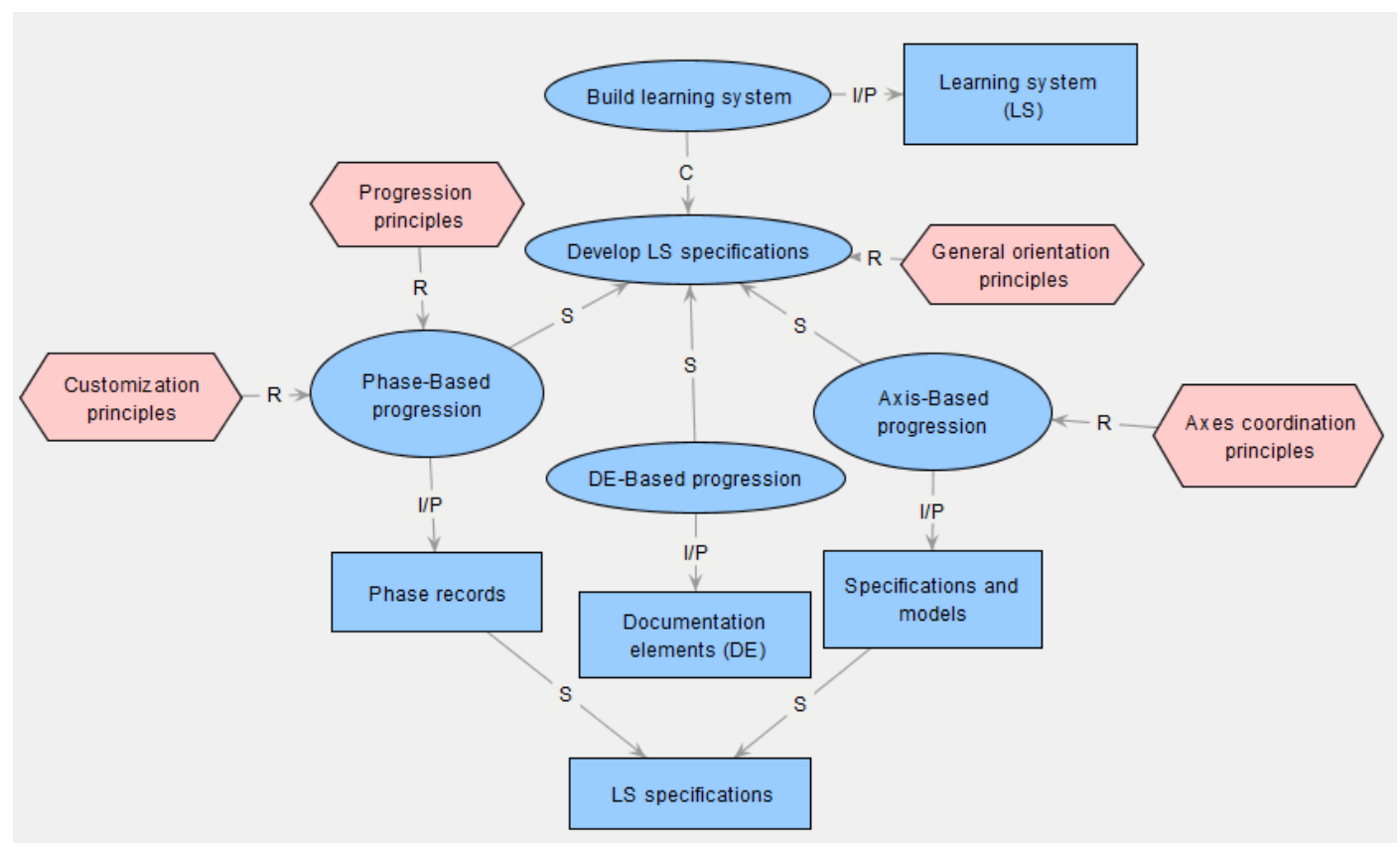

Fig. 2. Method for engineering learning systems (MISA) overview

Mobile Learning as defined previously encourages the presence of multimedia resources, digital media and dynamic interactivity between users and materials. The specification of the materials development orientation principles will be influenced by these constraints which will also take into account the adaptation of interfaces to high interactivity of materials required by the different learning situations and the technical characteristics of Mobile Learning. It will also specify the high level of assistance required by mobile users.

Mobile Learning is a situated and private learning. These characteristics must be taken into account in the implementation of the delivery orientation principles. Delivery should be based, in addition to learners' needs and preferences, on the context (e.g. using GPS). It must not invade the personal space and privacy of users and respect the schedules and delivery periods selected by the user. Instructional designers must consider the community concept of mobile learning (through social networks and blogs for example) in the definition of the composition and groups' management.

Customization principles enable the instructional designer to follow an itinerary that is custom-built for each project. Prior configuration of documentation elements at the beginning of the project or after the first phase is done according to the pedagogical approaches, delivery methods and scope of the learning system. In a mobile context, these principles will enable promoting, mobile learning educational approaches and strategies.

Customization principles enable the instructional designer to follow an itinerary that is custom-built for each project. Prior configuration of documentation elements at the beginning of the project or after the first phase is done according to the pedagogical approaches, delivery methods and scope of the learning system. In a mobile context, these principles will enable promoting, mobile learning educational approaches and strategies.

In the figure (Fig. 4) we have presented a part of the changes to be applied while specifying general orientation principles group subjects of the MISA method. The figure shows some new scenarios and tools generated by the use of mobile technology in the learning process.

Highlighting constraints that must be considered when developing the operating principles of MISA method is a first step in the adaptation process of MISA. Indeed, each specification must be analyzed to determine how it will influence the method's phases and axes. The various principles of MISA must consider the characteristics of mobile learning, its basic elements, and the learning style that introduces 


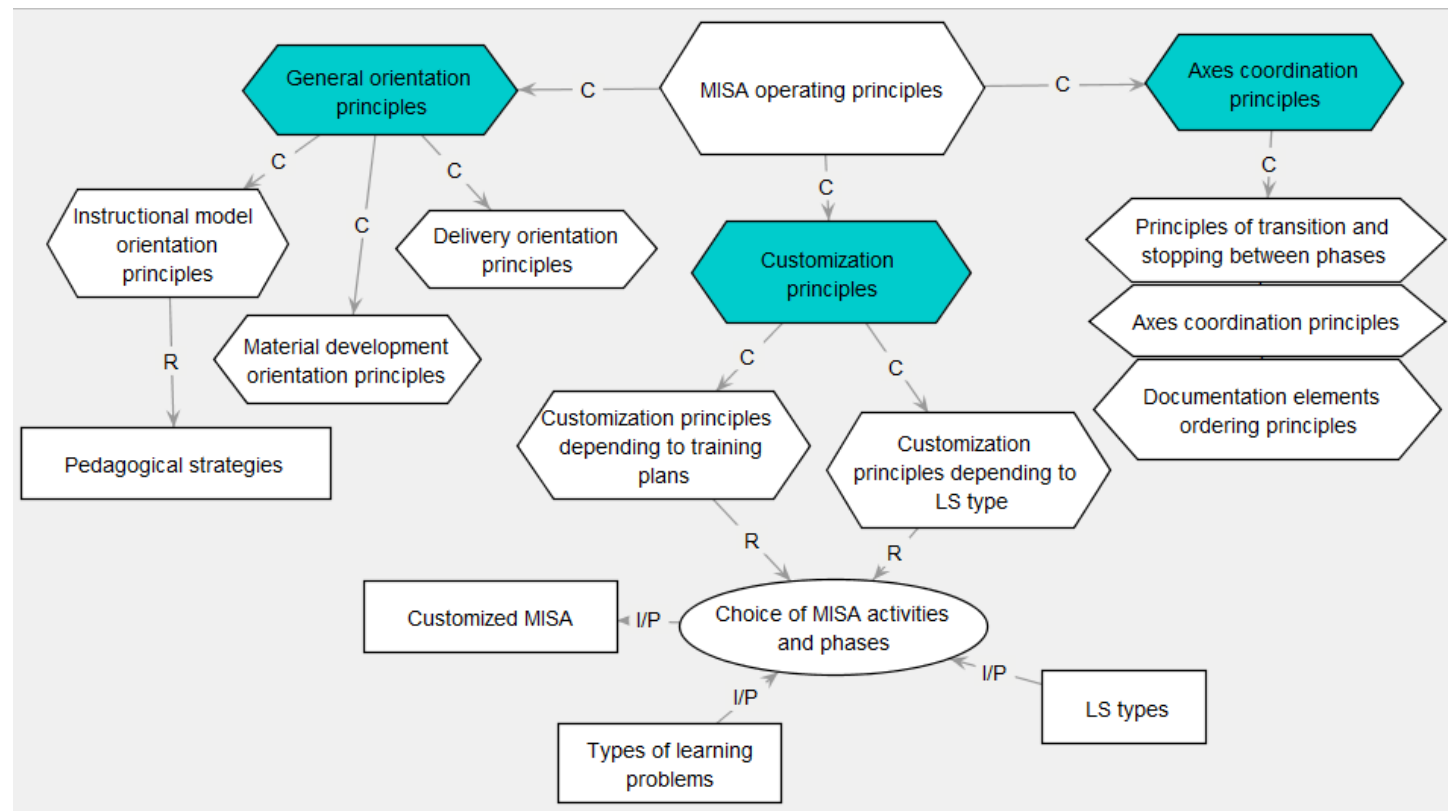

Fig. 3. MISA operating principles

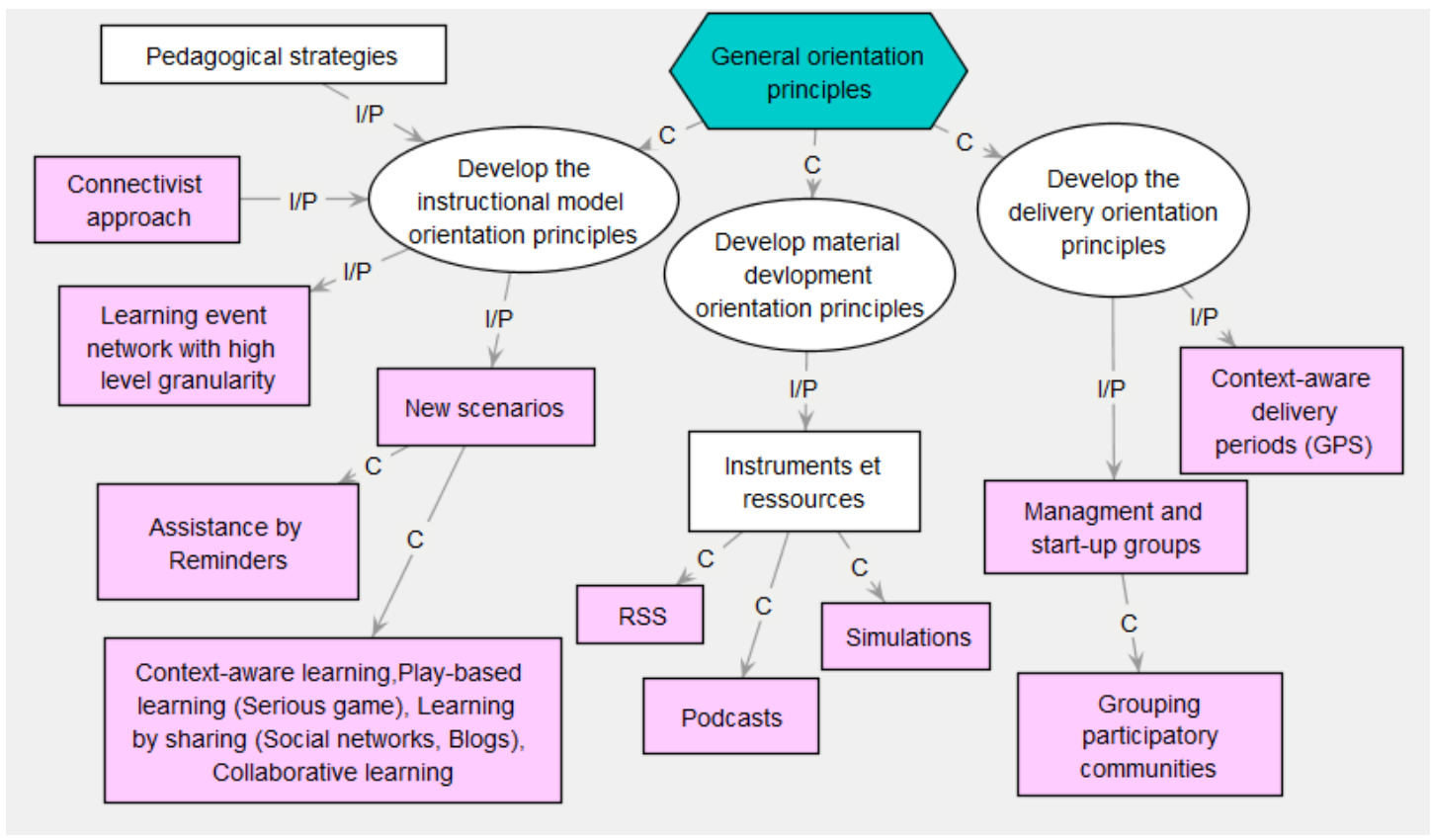

Fig. 4. Customized instrutional orientation principles

\section{CONCLUSION}

According to Gardner Inc. Smartphones sales increased by $46.9 \%$ in the third quarter of 2012 compared to the third quarter of 2011. The mobile devices use varies between GPS coordinates, payment by credit cards, data transfers, tasks organizing, communication, etc. [2]. These devices are becoming a daily presence in the life of people who want to be "always connected" [3]. Their advanced features allow using them in a learning context, giving users a possible solution to the continuing need for learning in a society increasingly mobile.

Mobile learning offers novel opportunities for existing educational systems. It allows immersion learning in the personal space of students who become not only consumers of educational content, but creators of new situations and learning activities.

Mobile learning theorization projects and studies are multiplying. They use various approaches and methodologies. Research has also begun to explore the 
perceptions and readiness of learners and educators for this new concept. The establishment of a pedagogical model integrating mobility as an essential component of learning is now a necessity.

Hooft calls to rethink what happens at school in the field of education. The school has become a process rather than a defined space and a fixed time entity [8].

Mobile learning seeks to restructure and develop learning systems to meet the increasingly growing need for mobility needs and lifelong learning. This learning style will extend teaching through new contexts. It takes into account the mobility of learners and communicative character that requires ongoing collaboration and exchange as well as the need to obtain relevant information where and when it is needed.

Highlighting different features and pedagogical considerations is only the first step of the process of theorizing mobile learning, which has proven to be indispensable for the delimitation of the problem. It is also a crucial step to adapting the method for engineering learning system MISA. The different steps of this method are governed by operating principles. These principles allow flexibility and adaptability of the method by giving greater freedom to the instructional designer. They also enable applying our own recommendations and guidance to design a mobile learning system.

Our work focuses on identifying these recommendations and guidelines for the execution of each task of the method according to the context of mobility. These specifications will incorporate appropriate new pedagogical types of learning scenarios, learning activities, new forms of collaboration and exchange.

\section{REFERENCES}

[1] Jackie Gerstein, Ed.D., «Education 3.0 and the Pedagogy ( Andragogy, Heutagogy) of Mobile Learning, 2013.

[2] R. Vala, L. Sarga, R. Benda, "Security Reverse Engineering of Mobile Operating Systems: A Summary". Recent Advances in Cimputer science. Proceedings of the $17^{\text {th }}$ International Conference on computers. Rhodes Island, Greece. July 16-19, 2013. ISBN: 978-960474-311-7. Published by WSEAS Press.

[3] F. Palumbo, G. Dominici, G. Basile, "Designing a mobile app for museums according to the drivers of visitor satisfaction". Recente Advances in Business Management and Marketing. Proceedings of the $1^{\text {st }}$ International Conference on Management, Marketing, Tourism, Retail, Finance and Computer Applications (MATREFC '13). Dubrovnik, Croatie, June 25-27, 2013. ISBN: 978-960-474-3063. Published by WSEAS Press.

[4] M. Vlainić, N. Mikelić Preradović, "A Comparative Study of Automatic Text Summarization System Performance". Proceedings of the $7^{\text {th }}$ European Computing Conference (ECC 13). Dubrovnik, Croatie, June 25-27, 2013. Recent Advances in Information Science. ISBN: 978-960-474-304-9

[5] S. Kinash, J. Brand and T. Mathiew, "Challenging mobile learning discourse through research: Students perceptions of Blackboard Mobile Learn and iPads", Australian Journal of Educational Technology, Vol. 28, No. 4, pp. 639-655, 2012.

[6] B. BATCHAKUI, T. DJOTIO, A. NGATCHUI, C. TANGHA, «Extension de VeSMEL pour la manipulation des contenus dans le m-learning », Volume 1- 2012, pages 1 à 8- ARIMA.

[7] J. Mahat, Ahmad Fauzi Mohd Ayub, Su Luan, Wong, «An assessment of Students' Mobile Self-Efficacy, Readiness and
Personal Innovativeness towards Mobile Learning in Higher Education in Malaysia », IETC2012, Procedia- Social and Behavioral Sciences 64 (2012) 284- 290.

[8] R. Thibert, « Pédagogie + Numérique = Apprentissage $2.0 »$, Dossier d'actualité veille et analyses, $\mathrm{n}^{\circ}$ 79, Décembre 2012.

[9] Nicola Louise Beddall-Hill, "It's not what you know but the device you know: The influence of ownership on appropriation of mobile devices for learning in field trips" Proceedings of 2011 mobile learning: crossing boundaries in convergent environments conference, Bremen, Germany, 2011.

[10] "UNESCO Mobile Learning Week Report (MLW)," United Nations Educational, Scientific and Cultural Organization (UNESCO), Paris, December 2011.

[11] G-J. Hwang, H-F. Chang, "A formative assessment-based mobile learning approach to improving the learning attitudes and achievements of students", Computer and education 56 (2011) 10231031.

[12] M. Ally, "Mobile Learning, Transforming the Delivery of Education and Training", M. Ally (eds.), AU Press, Athabasca University, 2009, Chap. 1, pp. 9-24.

[13] A. Kukulska-Hulme, M. Sharples, M. Milrad, I. Arnedillo-Sãnchez and G. Vavoula, "Innovating in Mobile Learning: a European Perspective", International Journal of Mobile and Blended Learning, 1(1), pp. 13-35, 2009.

[14] G. Vavoula, M. Sharples, P. Rudman, P. Lonsdale and J. Meek "Learning bridges: a role for mobile technologies in education", Educational Technology XLVII, pp. 33-36, 2007.

[15] M. Sharples, J. Sharples and G. Vavoula, "Towards a Theory of Mobile Learning" 2005.

[16] G. Siemens, «Connectivism: A learning Theory fir the Digital Age », 2005.

[17] Anna Trifonova, "Mobile learning-Review of the literature" Technical Report \#PDT-03-009, 2003.

[18] G. Paquette, "L’ingénierie pédagogique. Pour construire l'apprentissage en réseau", Presses de l'université du QUEBEC, 2002.

[19] G. Paquette, Book «Modélisation des connaissances et des compétences. Un langage graphique pour concevoir et apprendre», 2002, ISBN 2-7605-1163-4, 388 pages.

[20] G. Paquette, M. Léonard, I. de la Teja, M. Dessaint, « Méthode d'ingénierie d'un système d'apprentissage. MISA 4.0 Présentation de la méthode ", Centre de recherche LICEF, 2000.

[21] F. LIENARD, Communication « Du e-learning au m-learning : quels intérêts pour les apprentissages? », IUT Le Havre.

[22] Nor Alley Zukafly, Ah-Coo Koo, Tengku Putri Norishah Shariman, Mohd Nazri Zainuddin, "Educators' Perceptions towards Mobile Learning", unpublished.

\section{Creative Commons Attribution License 4.0 (Attribution 4.0 International, CC BY 4.0)}

This article is published under the terms of the Creative Commons Attribution License 4.0 https://creativecommons.org/licenses/by/4.0/deed.en US 